\title{
Trabalho, práxis e Serviço Social
}

\section{Renata Gomes da Costa}

Universidade Estadual do Ceará (UECE)

\author{
Maria Zelma de Araújo Madeira
}

Universidade Estadual do Ceará (UECE)

\section{Trabalho, práxis e Serviço Social}

Resumo: O presente artigo tem como objetivo discutir a práxis do Serviço Social a partir de uma reflexão ontológica sobre a categoria trabalho, diferenciando-a das outras práxis. Em seguida, aborda a função social do Serviço Social e, por fim, discute sobre a práxis do Serviço Social na contemporaneidade, enfocando suas relações e condições de trabalho.

Palavras-chave: Trabalho. Práxis social. Serviço Social.

\section{Work, Praxis and Social Work}

Abstract: The purpose of this article is to discuss the praxis of Social Work, based on an ontological reflection about the category of work, distinguishing it from other forms of praxis. It then addresses the social function of Social Work and finally discusses praxis of Social Work today, focusing on its labor relations and conditions.

Keywords: Labor. Social praxis. Social Work. 


\section{Introdução}

O Serviço Social é uma área que, nas últimas décadas, vem crescendo no Brasil, tendo passado por inúmeras transformações e reformulações resultantes da problematização dos seus aspectos teóricos, metodológicos e políticos. Como exemplo, tem-se o I Congresso Brasileiro de Serviço Social, em 1947, em que, mesmo sem ter uma temática central, serviu de ato preparatório para o II Congresso Pan-Americano de Serviço Social, realizado em 1949 na cidade do Rio de Janeiro.

Repensar a profissão a partir dos parâmetros teóricos e metodológicos ganha ênfase na década de 1960, momento de expansão do Serviço Social e de suas escolas, e se espraia até 1980, no período de (re)democratização da sociedade brasileira, após longos e violentos anos de ditadura militar. Nesses anos, que demarcaram o que Netto (1998) denomina de movimento de reconceituação, o Serviço Social passa a questionar e problematizar sua intervenção e produção científica.

Apenas na década de 1980, com a apropriação - não mais velada pelos ditames da ditadura militar - da teoria marxiana e marxista, a profissão vem construindo uma hegemonia norteada pela teoria crítica. No desencadear desse processo histórico, o Serviço Social foi se refazendo, negando o conservadorismo, o positivismo, as práticas voluntaristas e filantrópicas, partindo para um direcionamento ético e político em prol da classe trabalhadora, na luta pelo acesso aos direitos e pela legitimação de outros segmentos sociais.

Nesse contexto de renovação e crítica ao Serviço Social tradicional, passa-se a compreender a natureza da profissão e seus objetivos na sociedade, norteando-a com princípios e diretrizes interventivas, fundamentadas e determinadas por uma direção social que tem na liberdade seu valor central. Além de refletir sobre si mesmo, o Serviço Social passa, principalmente na década de 1990, a produzir conhecimentos sobre a atuação profissional, a realidade brasileira e as políticas sociais.

No decorrer dessas produções, que determinam veementemente a existência da profissão, surgem consensos e dissensos em relação a algumas temáticas, o que propicia um debate profícuo e bem fundamentado entre autores/as que servem de referência para a categoria profissional. Esse debate, tanto em espaços políticos como em produções teóricas, adensa os conhecimentos já existentes e cria novos. Uma das polêmicas instauradas no interior da categoria é se Serviço Social é ou não trabalho. Refletir sobre isso se faz importante ao sinalizar, de acordo com Lessa (2007b, p. 14), como os/as assistentes sociais concebem a história e a identidade da profissão. Essa polêmica não é vaga e ilegítima: antes de tudo, apresenta o nível de intensificação da produção encampada pelo Serviço Social nos últimos anos e "indica o desenvolvimento de sua relação mais rica e dinâmica com o conjunto das ciências humanas".

Analisar a atuação profissional como práxis social requer um entendimento do trabalho em seu sentido concreto e abstrato a partir dos processos históricos, enfocando as alterações na produção e reprodução das relações capitalistas que determinam mudanças nas condições e relações de trabalho.

Pesquisas e produções sobre a atuação profissional, seu estatuto de assalariamento, as configurações do mercado de trabalho, os condicionantes que incidem na autonomia profissional e a materialização ou não do projeto ético-político são questões que contribuem para o entendimento da profissão nos espaços sócioocupacionais, que, mesmo diante de suas especificidades, comungam dos mesmos ditames do sistema sociometabólico do capital. A reflexão sobre o projeto ético-político encontra-se intrinsecamente imbricada com a análise da práxis do Serviço Social na contemporaneidade. Como romper com o messianismo, o fatalismo e o voluntarismo no âmbito interventivo? Um dos caminhos possíveis pode ser o aprofundamento teóricocrítico de desvelamento dos limites e das possibilidades do fazer profissional.

\section{Trabalho e práxis social: um debate necessário}

Em uma época em que se propaga o fim do trabalho como eixo explicador do surgimento do indivíduo social, buscando reflexões sobre temas mais contemporâneos que explicitem contundentemente a realidade em que se vive, parece estranho e ultrapassado para alguns produzir e pensar sobre a ontologia do ser social, seu fundamento e seus desdobramentos. Engana-se quem considera a discussão sobre o trabalho em seu sentido ontológico algo ultrapassado e de menor valor, pois nenhuma outra produção e categoria científica conseguiu analisar, explicar e determinar o surgimento do ser social, das relações produtivas e reprodutivas da sociedade de modo geral, senão pelo trabalho.

Mas, qual a importância em se discutir a ontologia do ser social para o Serviço Social? Eis o mote principal a ser compreendido: só há existência social por conta do trabalho, uma vez que ele é a forma originária do agir humano (LESSA, 2007a). Assim, todas as práxis sociais ${ }^{1}$, aqui entendidas como atividades, práticas e ações dos sujeitos, têm seu nexo causador e fundador no trabalho em seu sentido ontológico. 
Com o desenvolvimento das forças produtivas, observa-se visivelmente uma proporção cada vez menor do trabalho envolvendo o intercâmbio do indivíduo com a natureza. No entanto, essa premissa não fundamenta a inexistência da centralidade do trabalho, devendo-se pautar e compreender as mediações interpostas entre a centralidade ontológica, política e cotidiana do trabalho e dos/as trabalhadores/as. Dessa maneira,

[...] o trabalho é sempre parte de uma totalidade social. [...] ser fundante não significa ser cronologicamente anterior, mas sim portador das determinações essenciais do ser social [...] que consubstanciam o salto da humanidade para fora da natureza (LESSA, 2002, p. 38).

Deve-se considerar não o trabalho no sentido singular, realizado individualmente pelos sujeitos, mas em sua totalidade, na síntese das singularidades que produz e reproduz socialmente. Lessa observa que as teorias que buscam determinar a não centralidade do trabalho normalmente se embasam na nova relação entre o trabalho em seu sentido ontológico e as outras práxis subsumidas à lógica do capital. Ancoram-se na destruição de antigos postos de trabalho, na eliminação de muitas das profissões tidas como tradicionais - ocasionadas pela reestruturação produtiva -, bem como no grande desenvolvimento tecnológico, aliado à desmobilização dos movimentos sociais, em destaque o movimento operário e sindical, e o grande crescimento do setor de serviços, para fundamentar a premissa de que o trabalho não é mais a categoria fundante do mundo dos homens e das mulheres. Para Lessa (2002, p. 47),

[...] as tentativas de substituir o trabalho como categoria fundante do mundo dos homens têm tido, até o momento, um endereço ideológico e político claro e determinador: a justificação das novas formas de sociabilidade que surgem com a metamorfose da regência do capital nas últimas décadas.

Nesse contexto, o desafio está em perceber a centralidade do trabalho mediante as transformações ocasionadas pelo capitalismo. Em vez de fundamentar a existência da sociabilidade na linguagem, na intersubjetividade, na política ou no mercado, o desafio teórico e intelectual coloca-se em desvendar o real, a essência que encobre a aparência dos fenômenos na contemporaneidade comandada pelo sistema capitalista, explicitando seus nexos causais e determinantes econômicos, sociais e políticos, sem perder de vista que

[...] a vida só pode existir tendo por base o ser inorgânico, e sem a natureza como um todo não pode haver ser social. A troca orgânica do ser social com a natureza é a mediação ontológica que possibilita que o ser social se constitua enquanto esfera ontológica particular no interior da totalidade do ser em geral. Na tradição marxista, tal mediação é o trabalho (LESSA, 2002, p. 67).

Perceber e analisar a existência social e suas práxis partindo do trabalho não significa pensar que todos os atos dos indivíduos reduzem-se ao trabalho. Temos que

[...] inúmeros atos humanos não podem ser reduzidos a atos de trabalho, em que pese o fato de o trabalho ser a forma originária e o fundamento ontológico das diferentes formas da práxis social [...] sem o trabalho [...] as inúmeras e variadas formas de atividade humano-social não poderiam sequer existir (LESSA, 2007b, p. 36).

Portanto, a existência humana é mais do que trabalho: ao passo que o ser social se relaciona com a natureza, relaciona-se também com outros sujeitos, surgindo necessidades que brotam das relações sociais entre si. O trabalho é uma articulação entre teleologias e causalidades ${ }^{2}$, pesando a distinção entre criador e criatura. Por terem uma história própria em relação ao sujeito que as gerou, as criações humanas podem agir sobre a história independentemente do sujeito.

Ao criar por meio do trabalho, o indivíduo transforma o seu meio e a si mesmo, uma vez que no fim do seu processo de trabalho angaria outros conhecimentos e aprendizados que, no início de seu empreendimento, ainda não detinha; "ao desenvolvimento do trabalho corresponde, paralelamente, o nascimento da consciência e do conhecimento humano" (IAMAMOTO, 2011, p. 351). Em resumo, o trabalho

[...] é uma atividade orientada a um fim para produzir valores de uso, apropriação do natural para satisfazer as necessidades humanas, condição universal do metabolismo entre homem e natureza, condição natural eterna da vida humana e, portanto, independente de qualquer forma dessa vida, sendo antes igualmente comum a todas as suas formas sociais (MARX, 2004, p. 38).

Por conter teleologias e causalidades em sua ação é que o trabalho humano se distingue do ato animal. O sujeito emprega, na execução de seu trabalho, a consciência por caracterizar-se como "um ser genérico e cons- 
ciente, isto é, um ser que se relaciona com o gênero como a sua essência própria ou consigo como ser genérico" (MARX, 1989, p. 155). Ao contrário do animal, que produz a partir da sua necessidade imediata, sem consciência, o ser humano produz a medida de qualquer espécie, sua produção é universal e não unilateral. Portanto,

[...] é precisamente ao trabalhar o mundo objetivo que o homem primeiro se prova de maneira efetiva como um ser genérico. Esta produção é a sua vida genérica operativa. Por ela, a natureza aparece com a sua obra e a sua realidade efetiva. O objeto do trabalho é, portanto, a objetivação da vida genérica do homem (MARX, 1989, p. 157).

Apenas quando compreendemos o conceito do trabalho em seu sentido ontológico, podemos aprofundar o entendimento do trabalho em seu sentido abstrato, isto é, da forma com que o capitalismo se apropriou dessa atividade e de outras práxis sociais para a criação de valores de trocas em prol da acumulação e do desenvolvimento da sociabilidade capitalista. A distinção entre trabalho concreto e abstrato, auxilia na análise da centralidade do trabalho:

Todo trabalho é, de um lado, dispêndio de força humana de trabalho, no sentido fisiológico, e, nessa qualidade de trabalho humano igual ou abstrato, cria o valor das mercadorias. Todo trabalho, por outro lado, é dispêndio de força humana de trabalho, sob forma especial, para um determinado fim, e, nessa qualidade de trabalho útil e concreto, produz valores de uso (MARX, 2012, p. 68).

O caráter útil do trabalho, através do intercâmbio do indivíduo com a natureza, produzindo conforme sua necessidade de sobrevivência, baseia-se na dimensão concreta e qualitativa. Ao se distanciar dessa dimensão concreta, o trabalho mantém-se

[...] enquanto condição 'necessária' para a integralização do processo de valorização do capital, do sistema produtor de mercadorias. Do que resulta que a dimensão 'concreta' do trabalho é também inteiramente subordinada à sua dimensão 'abstrata' (ANTUNES, 2011, p. 80).

Adentrar nesse capcioso terreno em que se produz e se reproduz a sociabilidade capitalista, buscando especificamente compreender a relação entre trabalho concreto e abstrato, torna-se essencial para o entendimento da profissão de Serviço Social. O cerne dessa análise é entender a profissão como expressão do trabalho social, mas saber identificá-la como uma práxis social, imersa na reprodução social e expressa enquanto trabalho abstrato. Tal assertiva esclarece as esparrelas teóricas que reproduzem o entendimento do Serviço Social como trabalho (em seu plano ontológico), ao passo que também evidencia a complexa dimensão de uma práxis reprodutiva, sua natureza, suas funções, seus desafios e possibilidades.

Pesquisar e analisar a atuação profissional nessa condição torna-se mais que salutar, já que suas ações, atividades e posturas estão condicionadas pela situação de trabalhador/a assalariado/a que convive com frágeis e flexíveis relações de trabalho, nesse sentido, o/a assistente social poderia ser inegavelmente identificado/ a como um/a 'trabalhador/a'. No entanto, o não entendimento dessa relação dos complexos sociais torna necessário especificar essa prática como trabalho útil e concreto, denominado pela teoria marxiana como intercâmbio do sujeito com a natureza, produtor de valores de uso.

As polêmicas e distorções referentes ao entendimento do Serviço Social como práxis social e não como trabalho, e todos os dimensionamentos que decorrem desse debate, evidenciam a necessidade de aprofundar essas reflexões. Desvendar as condições e relações de trabalho é algo primordial para compreender os nexos causais que se interpõem na materialização do projeto ético-político da profissão, expresso também nas dimensões ético-políticas, teórico-metodológicas e técnico-operativas da práxis do/a assistente social. Compreender que o Serviço Social não é trabalho no sentido ontológico não negligencia a categoria trabalho para a profissão, mas trata de desvelar o processo de trabalho na constituição do ser social e saber como este se apresenta no capitalismo, que tem como base de sociabilidade a valorização e acumulação de capital.

Quando se fala em crise do trabalho, deve-se salientar, como aborda Antunes (2011), que a crise não é do trabalho concreto, mas sim do trabalho abstrato. O "sistema sociometabólico do capital" subordina a totalidade dos atos do trabalho à sua lógica, dando base para justificativas que apregoam o desaparecimento do trabalho, fundante do ser social, e sua substituição pelo trabalho abstrato:

[...] na imediaticidade de nossa vida cotidiana, como as atividades que operam o intercâmbio orgânico com a natureza podem ser também convertidas em produtoras de mais-valia, não raras vezes essas duas funções tão distintas são indevidamente confundidas. E, hoje, com a extensão das relações capitalistas até pratica- 
mente todas as formas de práxis social, com a incorporação, ao processo de valorização do capital, de atividades que anteriormente ou estavam dele excluídas ou apenas participavam de modo muito indireto, vivemos uma situação em que praticamente a totalidade dos atos de trabalho assume a forma abstrata advinda de sua subordinação ao capital. Aparentemente, o trabalho teria desaparecido, substituído pelo trabalho abstrato. Trabalho e trabalho abstrato passam, assim, equivocadamente a ser tomados como sinônimos no caso da sociabilidade contemporânea (LESSA, 2002, p. 28).

Existe uma diferença metodológica imensa na consideração do Serviço Social ser ou não trabalho, o que culmina na sua organização política como categoria. Trazendo as conceituações e diferenciações da categoria trabalho e compreendendo que outras práxis sociais, como o Serviço Social, não se caracterizam como trabalho em seu sentido concreto (ontológico), abordaremos a função social que essa profissão tem na sociedade, como foi implementada e qual sua serventia.

\section{Serviço Social como práxis social}

O trabalho é a categoria fundante do mundo dos homens. Essa afirmativa é basilar para o entendimento do ser e da existência social. O intercâmbio do indivíduo com a natureza é projetado pela consciência antes de ser efetivado praticamente, possibilitando, assim, escolhas entre alternativas a serem objetivadas, transformando a realidade e produzindo novas situações. Além disso, se o trabalho propicia a construção e a transformação do mundo objetivo, bem como do sujeito que trabalha por meio da apreensão de outros conhecimentos e habilidades, surgem novas necessidades, então: "se o trabalho é fundante do ser social, funda também a reprodução social e todos os outros complexos sociais - o Serviço Social incluso - são fundados por ele" (LESSA, 2007b, p. 29).

Compreendendo que o trabalho funda a reprodução social e outros complexos sociais, como definir o Serviço Social como trabalho concreto e abstrato? O que é essa profissão? E qual sua função social?

Ao tratar da reprodução social como uma esfera fundada pelo trabalho concreto, deve-se salientar que seu desenvolvimento estará articulado com a história das formações sociais, ou seja, a reprodução social no primitivismo, no escravismo, no feudalismo e no capitalismo segue as particularidades históricas de cada momento. Visto sua distinção e interligação com a categoria trabalho. Lessa (2007b) aponta três elementos primordiais: a integração da vida social que passa dos pequenos grupos, da divisão em bandos, para o compartilhamento de uma mesma história; a complexificação e heterogeneidade das sociedades; e o desenvolvimento e a complexificação dos indivíduos.

Esses fatores demonstram que a heterogeneidade das sociedades e dos indivíduos ocasiona a criação de outras relações, instituições e complexos sociais, a fim de articular, em uma única história, toda a vida social, ou seja,

[...] para articular a vida de todos os indivíduos em uma única história, o desenvolvimento social necessitou de um elevado número de novos complexos sociais, de novas mediações, que o tornaram muito mais contraditório, diferenciado e heterogêneo se comparado com o seu ponto de partida. A crescente heterogeneidade, portanto, não apenas não se contrapõe como é uma necessidade para o desenvolvimento de relações sociais crescentemente genéricas que articulam o destino de cada indivíduo ao destino de toda humanidade (LESSA, 2007b, p. 41).

A compreensão da reprodução social e de sua expressão histórica oferece subsídios analíticos na apreensão do trabalho concreto e de outras práxis sociais, pois, "no estudo dos casos singulares da práxis social, muitas vezes não possamos distinguir, a não ser por uma análise muito particularizada, um ato de trabalho de um ato pertencente à esfera da reprodução social" (LESSA, 2007b, p. 41). Aqui se chega ao "calcanhar de Aquiles" dessa discussão: observar atos singulares de trabalho por si mesmo ocasionará, possivelmente, uma confusão entre trabalho concreto e trabalho abstrato. Entretanto, o que deve ser posto em "xeque" é a função social desse ato analisado. Para isso, destaca-se a construção analítica realizada por Lessa sobre o trabalho concreto e outros complexos sociais, a partir da diferença entre a práxis social do professor, do assistente social e do operário em três pontos de vista: da formalidade, da materialidade e da função social.

Concernente à formalidade, não existe nenhuma distinção: os três profissionais possuem atos similares, ao considerar que partem de uma prévia ideação, objetivam, realizam a síntese entre teleologias e causalidades, transformam o real e, no final de sua ação, deparam-se com algo novo.

Refletindo sobre a materialidade, tem-se que todos são trabalhadores assalariados; que as diferenças são subsidiárias em relação ao ambiente de trabalho; que as distintas ferramentas utilizadas e os diferentes 
produtos produzidos são, na verdade, trabalho abstrato, "todos os três profissionais são 'trabalhadores' no sentido comum: vendem as suas forças de trabalho em troca de um salário" (LESSA, 2007b, p. 44).

É somente quanto à sua função social que se pode distinguir o trabalho concreto das outras práxis, demonstrando sua especificidade e particularidade:

[...] a distinção entre o trabalho e as outras práxis sociais não está nem na sua forma, nem na sua 'materialidade', nem na qualidade ontológica do seu objeto, e muito menos na sua relação com a produção da mais-valia. $\mathrm{O}$ que torna o trabalho a categoria fundante - e todas as outras práxis sociais fundadas - é sua função social. É a função social do trabalho que o distingue de todas as outras formas de atividade humana, independentemente de semelhanças eventuais [...]. Para Marx, o trabalho possui uma função social muito precisa: faz a mediação entre o homem e a natureza, de tal modo a produzir a base material indispensável para a reprodução das sociedades. O trabalho é a práxis social que produz os meios de produção e de subsistência sem os quais a sociedade não poderia sequer existir. Esta é a função social do trabalho e isto é o que o distingue das outras práxis sociais (LESSA, 2007b, p. 45).

A questão não é apenas entender as implicações do trabalho do/a assistente social no circuito do valor, da produção e distribuição da mais-valia, mas sim compreender que o trabalho, em seu sentido concreto, para se efetivar na sociedade - tanto a primitiva e muito mais a capitalista - requer outras atividades que produzam as condições sociais necessárias. Isso não minimiza essas práxis sociais, não as fazem menores em importância: ao serem tidas como atos preparatórios, tornam-se indispensáveis à existência humana. Trabalho concreto e outras práxis são essenciais para a reprodução social, uma vez que, como afirma Lessa (2007b, p. 47), "se uma sociedade se limitasse a preparar os atos de trabalho, mas não transformasse a natureza, sua reprodução seria impossível".

Dessa maneira, tem-se um problema filosófico ao igualar o Serviço Social ao trabalho concreto, buscando denominar, na práxis do/a assistente social, matéria-prima, meios de produção e produto o que não facilita na identificação e instrumentalidade da profissão, pois

[...] significa igualar o intercâmbio orgânico com a natureza, com outras atividades em tudo distintas. Ao cancelar o que o trabalho tem de específico, isto é, cumprir a função social de transformar a natureza em meios de produção e de subsistência, dissolve-se o trabalho em um enorme conjunto de práxis e, consequentemente, cancela-se a tese marxiana de ser o trabalho a categoria fundante do mundo dos homens (LESSA, 2007b, p. 28).

Outro fator primordial nessa discussão sobre a diferenciação entre trabalho concreto e outras práxis refere-se ao desenvolvimento das causalidades. Como afirma Lessa (2007b), no caso do trabalho concreto a causalidade que o sujeito transforma é a natureza; no caso das outras práxis, que o autor também define como atos preparatórios do trabalho, o objetivo é a organização dos sujeitos e de seus comportamentos, seja pelo convencimento ou repressão, interferindo na consciência das pessoas, visando a uma determinada finalidade. Assim, as ações empreendidas pelo/a professor/a, policial ou assistente social "desencadeiam outras posições teleológicas e não processualidades naturais. Ou seja, o resultado 'concreto' [...] da atividade do professor e do assistente social é outro ato teleologicamente posto e não um carro" (LESSA, 2007b, p. 48).

Diante disso, compreende-se que a distinção entre os indivíduos está imbricada num critério produtivoeconômico, na relação entre quem produz a riqueza material e quem vive da riqueza produzida. Aqui se insere também a discussão entre trabalho produtivo e improdutivo, de quem produz a mais-valia e de quem vive da mais-valia produzida.

Conforme Lessa (2007a), o debate sobre trabalho produtivo e improdutivo por vezes centra-se no equívoco de pensar que não há diferenciações entre tais, que pode ser explicado pela diminuição da distância entre eles. Não se deve considerar que o trabalho produtivo é sinônimo de trabalho concreto: trabalho produtivo e improdutivo são duas expressões do trabalho abstrato, possuindo funções ontológicas distintas. Essa confusão pode ser ocasionada pela particularidade histórica fundada pelo capital, que transforma o trabalho concreto em abstrato, surgindo, na aparência dos fenômenos, similaridades que são tidas como sinônimos.

Nesse duplo aspecto que envolve o trabalho concreto, não se suprimem as particularidades destes em relação às outras práxis. Como já assinalado, nem tudo é trabalho em seu sentido ontológico. Mesmo que o capitalismo busque encobrir a essência dos fenômenos, deve-se desvendá-los e desmistificá-los, tendo como grande aporte a teoria crítica, que faz compreender como esse sistema produz e reproduz socialmente, afinal "nem todo trabalho produtivo realiza o intercâmbio orgânico com a natureza, sendo, por isso, indevida qualquer aproximação excessiva ou mesmo a identificação entre o trabalho produtivo e o trabalho enquanto 
fundante do mundo dos homens" (LESSA, 2007b, p. 33). A distinção entre trabalho produtivo e improdutivo só faz sentido sob o ponto de vista do capital que, através da extração de mais-valia, do tempo de trabalho excedente no decorrer do processo produtivo, determina a valorização e a acumulação de capital. Assim sendo, produtivo é o trabalho que produz mais-valia, e improdutivo é aquele que não produz. Os/as trabalhadores/as improdutivos/as apresentam-se, em maior número, de maneira heterogênea, vivendo da mais-valia produzida pelos/as trabalhadores/as produtivos/as (LESSA, 2007b).

Lessa (2007b) evidencia que o trabalho produtivo tem duas funções sociais: o trabalho proletário, que produz o capital, e o não proletário, que apenas gera a mais-valia pela conversão de riqueza existente em dinheiro, como no caso do/a professor/a de escola privada ou do/a assistente social de uma empresa. $\mathrm{O}$ objetivo do capitalismo é produzir e acumular cada vez mais capital. Suas mercadorias e produtos contêm tempo de trabalho não pago, mesmo porque

A acumulação do capital se faz pela apropriação da mais-valia. Como a mercadoria, no sistema capitalista, pode ser tanto a natureza transformada (o martelo) como um serviço (uma aula, um show de música etc.), em todos esses casos o burguês pode extrair mais-valia e acumular capital. A fonte da mais-valia pode ser tanto o trabalho do operário (que atua sobre a natureza) como o do cantor (que não atua sobre a natureza) [...]. Diferente dos modos de produção passados, portanto, a burguesia conseguiu, com o capitalismo, uma fonte de riqueza muito mais ampla e dinâmica, pois agora consegue acumular capital não apenas do trabalho que transforma a natureza, mas também de uma enorme gama de atividades (LESSA, 2007b, p. 71).

Percebe-se, dessa maneira, que o/a assistente social e o/a operário/a se aproximam por sua inserção no mercado de trabalho, como trabalhadores/as assalariados/as, mas não como trabalhadores/as em seu sentido concreto. Afirmar que um/a trabalhador/a não realiza trabalho e, ademais, é improdutivo/a, não nega sua condição de classe trabalhadora, mas sim contribui para se pensar na heterogeneidade dessa classe em tempos de capital fetiche.

\section{Práxis social do/a assistente social na contemporaneidade}

Refletir sobre a profissão de Serviço Social na contemporaneidade torna-se um desafio ao ter de desvendar as complexas transformações empreendidas pelo capitalismo no final da década de 1970 e início da de 1980. As referidas mudanças foram se gestando em um cenário em que as dívidas públicas e privadas cresceram contundentemente e a primeira grande recessão, catalisada pela alta dos preços do petróleo em 1973/1974, foram os sinais de que o pleno emprego e a cidadania relacionada à proteção social estavam se desfazendo nos países europeus e nos EUA, comprometendo também as nações periféricas, em que o Estado de bem-estar não se realizou plenamente.

As elites político-econômicas, então, começaram a questionar e a responsabilizar, pela crise, a atuação agigantada do Estado, especialmente naqueles setores que não revertiam diretamente em favor de seus interesses. Aliada a esse contexto, tem-se a grande revolução tecnológica: um salto na automação, na robótica e na microeletrônica, que invadiu o espaço fabril e a sociedade como um todo, o que incidiu nas relações e condições de trabalho, bem como na produção e na acumulação do capital (ANTUNES, 2011).

A reinvenção do liberalismo, promovida pelos neoliberais no final dos anos 1970 e 1980, espraiando-se na década de 1990 em todo o mundo, foi uma reação teórica e política ao keynesianismo e ao Estado de bem-estar social. Com o toyotismo, alicerçado pela acumulação flexível, a produção torna-se variada, diversa, destinada à demanda. Suprem-se os grandes estoques e a produção em massa, a produção se organiza a partir de um estoque mínimo e a

Engana-se quem considera a discussão sobre o trabalho em seu sentido ontológico algo ultrapassado e de menor valor, pois nenhuma outra produção e categoria científica conseguiu analisar, explicar e determinar o surgimento do ser social, das relações produtivas e reprodutivas da sociedade de modo geral, senão pelo trabalho. obsolescência programada dos produtos ganha ênfase nesse modelo produtivo. Ao ser uma resposta à crise do fordismo na década de 1970, em vez de um trabalhador especializado, exige-se um operário polivalente, que se 
integre a uma equipe e realize tarefas múltiplas, passando a produzir conforme a demanda do consumidor em sua satisfação, empregando a ideologia do controle de qualidade. Entretanto, deve-se ponderar que

[...] a substituição do fordismo pelo toyotismo não deve ser entendida, o que nos parece óbvio, como um novo modo de organização societária, livre das mazelas do sistema produtor de mercadorias e, o que é menos evidente e mais polêmico, mas também nos parece claro, não deve nem mesmo ser concebido como um avanço em relação ao capitalismo da era fordista e taylorista. [...] a diminuição entre elaboração e execução, entre concepção e produção, que constantemente se atribui ao toyotismo, só é possível porque se realiza no universo estrito e rigorosamente concebido do sistema produtor de mercadorias, do processo de criação e valorização do capital (ANTUNES, 2011, p. 39).

As consequências dessas transformações e modificações empreendidas pelo sistema capitalista em prol de sua sobrevivência e reprodução tiveram nefastas consequências para o mundo do trabalho, para trabalhadores/as que vendem sua força de trabalho em prol da sobrevivência. Ocorre uma maior heterogeneização, fragmentação e complexificação da classe trabalhadora, tem-se uma diminuição do trabalho fabril, da classe operária industrial tradicional e um aumento do trabalho precário e assalariado, principalmente no setor de serviços.

Com todas essas mudanças no processo produtivo e sua consequência imediata no mundo do trabalho, uma gama de profissionais passa a conviver em seu cotidiano com a realidade do desemprego e das terceirizações. Nessa complexa configuração do trabalho na sociedade capitalista, insere-se a práxis do Serviço Social que se apresenta nessa dinâmica contemporânea como trabalho abstrato, assalariado, implicando as competências, atribuições e capacidade técnico-profissional, subordinando precariamente as dimensões teórico-metodológicas, técnico-operativas e ético-políticas do fazer profissional.

Iamamoto (2011) afirma que o maior empregador de assistente social é o Estado, na implementação, execução e elaboração das políticas sociais, que, nesse contexto neoliberal, também vai sofrer contundentemente em sua gestão. Para Behring (2008), a contrarreforma do Estado vem implicando esse redirecionamento das políticas sociais, o que tem incidido negativamente nas condições de trabalho dos/as profissionais que intervêm nessa realidade, como os/as assistentes sociais. Conforme a autora, do ponto de vista físico, tem-se um leque de dificuldades para implementação de políticas que se apresentam como pobres para os pobres, focalizadas e residuais. Convive-se, dessa maneira, com estruturas institucionais precárias, sem condições de preservar o sigilo profissional, com ausência de mobília adequada para os atendimentos, de equipamentos que prezem pelo registro desses atendimentos e de material a ser usado no cotidiano de trabalho. O contexto em que se apresentam demonstra que

[...] as consequências das profundas alterações nas condições de trabalho, na forma de contrato da força de trabalho ocupada e na gestão da força de trabalho excedente, determinam e atingem o trabalho do assistente social e a forma de contratação de sua força de trabalho, pois não há possibilidade de o trato da 'questão social' ser aviltada e de, ao mesmo tempo, existirem condições generosas interferindo nesse processo (GRANEMANN, 2009, p. 162).

Depara-se, assim, com a desvalorização e a superexploração da força de trabalho em prol da valorização e da acumulação do capital. As contratações seguem a lógica do capitalismo, o mundo do trabalho se reordena em prol dos imperativos desse sistema, fortalecem-se os serviços privados. O que é direito constitucionalmente estabelecido, como saúde e educação, devendo ser garantido pública, universal e gratuitamente, passa a status de mercadoria, de serviço, de produto a ser comprado. O que deveria ser direito adquirido pelo sujeito apresenta-se como problema de consumidor que o comprou a partir das regras do mercado. Verifica-se a precarização, a instabilidade do não direito, a fragmentação da questão social, a responsabilização do sujeito individual por seu lugar na vida social, a política social diferenciada para as frações da força de trabalho.

Essas transformações no mundo do trabalho, nas políticas sociais, no acesso aos direitos repercutem na atuação do/a assistente social, com a tendência de uma redefinição do próprio trabalho profissional, reduzindoo a plantões de emergência. Limita-se a mero/a executor/a de tarefas, à rotinização da atuação, à ênfase nos relatórios quantitativos em prol da produtividade. Diminui-se o tempo para se planejar as ações, para estudar, organizar e refletir sobre os projetos existentes e a elaboração de novos. O que se torna primordial é a gestão da pobreza e de políticas pobres para os pobres (GRANEMANN, 2009).

Nesse bojo de relações e contradições, vale ressaltar que esse processo de precarização do trabalho profissional ocorre também no setor privado, através dos contratos precários da supressão dos direitos. O debate sobre a atuação do Serviço Social tem de considerar os diferentes espaços sócio-ocupacionais, suas particularida- 
des, natureza, objetivos e demandas. O que se deseja observar é que mesmo a pauperização e a privatização dos serviços, com expressões distintas conforme as finalidades institucionais, estão interligadas a um bojo maior de relações econômicas, sociais, políticas e culturais, determinadas e comandadas pelo sistema capitalista.

Eis o desafio ao se pensar o Serviço Social na contemporaneidade: entender, primeiro e principalmente, sua função social como práxis social - ademais, o local que ocupa na produção e reprodução da vida material, no circuito de produção da mais-valia. Parte-se para o desvendamento de sua atuação cotidiana em tempos neoliberais, buscando contribuir com sua ação profissional na defesa intransigente de seus princípios éticos de uma atuação pautada e fundamentada em valores democráticos e humanos, tendo como horizonte último a construção de uma nova sociabilidade. Esse desafio não pode ser tomado como missão primeira e única da categoria dos/as assistentes sociais, mas sim deve se articular com um projeto societário que lute pela emancipação humana em prol de uma sociedade sem exploração e dominação de classe, raça/etnia, gênero e diversidade sexual.

\section{Considerações finais}

Diante do exposto, observa-se que a compreensão da práxis do Serviço Social torna-se imprescindível ao identificá-lo como trabalho abstrato que sofre todas as refrações impostas pelo sistema capitalista, que se espraia a tantos/as outros/as que sobrevivem a partir da venda de sua força de trabalho em troca de salário. Compreender tal questão, sedimentada no entendimento do trabalho concreto como fundante do ser social e de toda existência humana, torna-se mais que salutar ao nos possibilitar desvendar a função social da profissão.

Entender essa função social pode não ter incidência decisiva e direta a/ao profissional na sua intervenção, mas tem em sua ação política ao debater sobre sua condição de trabalhador/a e sua organização política enquanto classe. Ao discutir sobre sua função social, chega-se ao debate sobre seu caráter de trabalho abstrato, que possibilita a compreensão das condições e relações de trabalho enfrentadas pelo/a profissional na contemporaneidade.

O Serviço Social é uma atividade inscrita na divisão social e técnica do trabalho, com atribuições e objetivos específicos, atuando no âmbito político e ideológico através dos serviços, programas e projetos previstos pelas políticas sociais, com sua atuação incidindo diretamente nas condições de vida dos sujeitos que atende, comprometida com a defesa dos direitos humanos, liberdade, democracia, entre outros elementos.

De tal modo, o Serviço Social é uma profissão que se consolidou como especialização do trabalho coletivo na maturação da sociedade capitalista, tendo por objeto interventivo as múltiplas expressões da questão social. Sua formação e materialização são perpassadas por uma historicidade que deve ser analisada e problematizada, pautando seus desafios históricos e sociais e a constituição teórica e interventiva, sem perder de vista a articulação com a totalidade social fundamentada na teoria crítica. Nesse sentido, a discussão teórica e política sobre sua função social é central nesse debate.

Afirmar que o Serviço Social não é trabalho em nada diminui sua importância como profissão, nem mesmo retira a importância primordial da identificação com a discussão sobre o trabalho, categoria-cerne para se entender a natureza e a identidade profissional.

\section{Referências}

ANTUNES, R. Adeus ao trabalho? Ensaio sobre as metamorfoses e a centralidade do mundo do trabalho. São Paulo: Cortez, 2011. BEHRING, E. R. Brasil em contrarreforma: desestruturação do Estado e perda de direitos. São Paulo: Cortez, 2008.

GRANEMANN, S. Ofensiva do capital e novas determinações do trabalho profissional. Revista Katálysis, Florianópolis: Edufsc, v. 12, n. 2, p. 161-169, jul./dez. 2009. Disponível em: <http://www.scielo.br/pdf/rk/v12n2/05.pdf〉. Acesso em: 12 jun. 2012.

IAMAMOTO, M. V. Serviço Social em tempo de capital fetiche: capital financeiro, trabalho e questão social. São Paulo: Cortez, 2011. LESSA, S. Mundo dos homens: trabalho e ser social. São Paulo: Boitempo, 2002.

. Para compreender a ontologia de Lukács. Ijuí: Unijuí, 2007a.

. Serviço Social e trabalho: porque o Serviço Social não é trabalho. Maceió: Edufal, 2007b.

MARX, K. Trabalho alienado e superação positiva da auto-alienação humana (Manuscritos econômicos e filosóficos - 1844). In: FERNANDES, F. (Org.). Marx e Engels. São Paulo: Ática, 1989. (Coleção Grandes Cientistas Sociais).

. Processo de trabalho e processo de valorização. In: ANTUNES, R. (Org.). A dialética do trabalho: escritos de Marx e Engels.

São Paulo: Expressão Popular, 2004.

O capital: crítica da economia política. Livro I. Tradução de Reginaldo Sant'anna. Rio de Janeiro: Civilização Brasileira, 2012.

NETTO, J. P. Ditadura e Serviço Social. São Paulo: Cortez, 1998. 


\section{Notas}

1 Em uma definição mais completa, temos que a práxis social, "como qualquer ato social, é uma decisão entre alternativas efetuada pelo indivíduo singular, que faz escolhas acerca de propósitos futuros visados. Porém, não faz escolhas independentes das pressões que as necessidades sociais exercem sobre os indivíduos singulares, interferindo nos rumos e orientações de suas decisões" (IAMAMOTO, 2011, p. 254).

2 De acordo com Lessa (2007a), todo ato de trabalho é precedido pela prévia-ideação: o sujeito prevê, projeta e planeja a ação, estando orientado por uma finalidade, uma teleologia, contando com as causalidades, ou seja, os nexos causais, a natureza e os objetos do mundo objetivo.

\section{Renata Gomes da Costa}

renatagomesdc@yahoo.com.br

Mestranda em Serviço Social, Trabalho e Questão Social na Universidade Estadual do Ceará (UECE)

\section{Maria Zelma de Araújo Madeira}

zelmadeira@yahoo.com.br

Doutora em Sociologia pela Universidade Federal do Ceará (UFCE)

Professora no Curso de Mestrado da UECE

\section{UECE - Departamento de Métodos e Técnicas do Serviço Social}

Av. Paranjana, 1700

Itaperi

Fortaleza - Ceará - Brasil

CEP: 60740-000 